\title{
The TRRL hydrograph method of urban sewer design adapted for tropical conditions
}

\author{
L. H. WATKINS
}

\section{Mr C. H. Clifton, Clifton Scannell Emerson Associates}

The Paper carries the basis of design of urban storm sewers as embodied in the TRRL approach a step further in order to deal with conditions which, in tropical countries, are such as to necessitate modification in certain aspects of the criteria deemed applicable in these latitudes. I use the word 'storm' because much progress on the approach to efficient design of storm (i.e. surface water) sewers has been made over the years, but I wonder whether there has been comparable progress in the design of completely separate foul sewerage systems?

59. It seems to me that the time lag factor, which is so important in the design of storm systems, could be examined more closely than I think has been the case in relation to the completely separate foul system, particularly for new systems (of a rather large nature). In essence, it seems to me that many may size pipes in a completely separate system on the basis of an upstream contribution consisting of the aggregate of a notional figure in gal/h per day, plus a figure for infiltration. CP $2005^{9}$ appears to offer little further guidance.

60. In fact, the approach referred to appears to me to tend towards a probability that pipes in the lower regions of the system may be oversized because the lag factor may not have been appreciated. Assuming a pipe velocity of $3 \mathrm{ft} / \mathrm{s}$, the foul sewerage will travel through the system at a rate of $180 \mathrm{ft} / \mathrm{min}$. In a system, say, 2 miles long the time of travel for foul sewerage from head to outfall would be almost one hour.

61. While this example is deliberately naive, perhaps it points to a necessity for a closer examination of the lag factor in the design of separate foul systems. Perhaps also further consideration should be given to the possibility of providing staged retention ponds on separate foul systems. They could serve the dual purpose of equalizing flow and providing partial treatment, thus reducing the purification loading on terminal treatment plants.

\section{Mr R. Hepworth, M}

It worries me that the Author continues to pursue his belief in the TRRL method in the face of criticism from other engineers well versed in surface water drainage design. The assumptions of the TRRL method are

(a) time of entry is short

(b) full bore velocities apply after the initial time of entry

(c) a typical recession curve exists and this occurs on every critical rainfall event.

Paper published: Proc. Instn Civ. Engrs, Part 2, 1976, 61, Sept., 539-566. 
63. The Author may agree that these assumptions are made and may argue that the retention correction is applied to overcome discrepancies between theory and practice brought about by assumption (b). In fact if either of assumptions $(a)$ or $(b)$ is inaccurate, which they both are, then the method becomes untenable. This is because the happenings at the start of the storm are indeterminate. They cannot be represented by a short time of entry. Assumption $(c)$ is also inaccurate because critical storms for an area do not necessarily cover the whole of the area and the recession curve can vary substantially for different storms.

64. Notwithstanding these facts the method can be demonstrated to be accurate in correlation but the reasons for this accuracy are not those which the Author gives. While the method can be accurate in correlation this does not mean that it is accurate in design. In fact the correlation and design procedures vary in important aspects.

65. The method is purely a geometrical construction which establishes a secondary hydrograph, enclosing the same area as the primary hydrograph and therefore representing the actual volume discharged. Also, the part of the secondary hydrograph after the end of the primary hydrograph takes the exact shape of the recession curve specifically chosen as being typical of the catchment (see Fig. 21).

66. While in correlation the primary hydrograph encloses the actual volume which ran off the paved area by virtue of application of the percentage run-off factor, in design percentage run-off is not applied and the area under both the primary and secondary hydrographs is likely to be in error. Thus a grossly inaccurate answer is possible in design. If a typical recession curve were to exist for the area, the later part of the secondary hydrograph would be correct because the shape is exactly the same as the assumed recession curve, but the earlier part of the secondary hydrograph is, without doubt, in error because all parts of the catchment area cannot possibly be contributing to a sewer length after the arbitrary, short time of entry allowed.

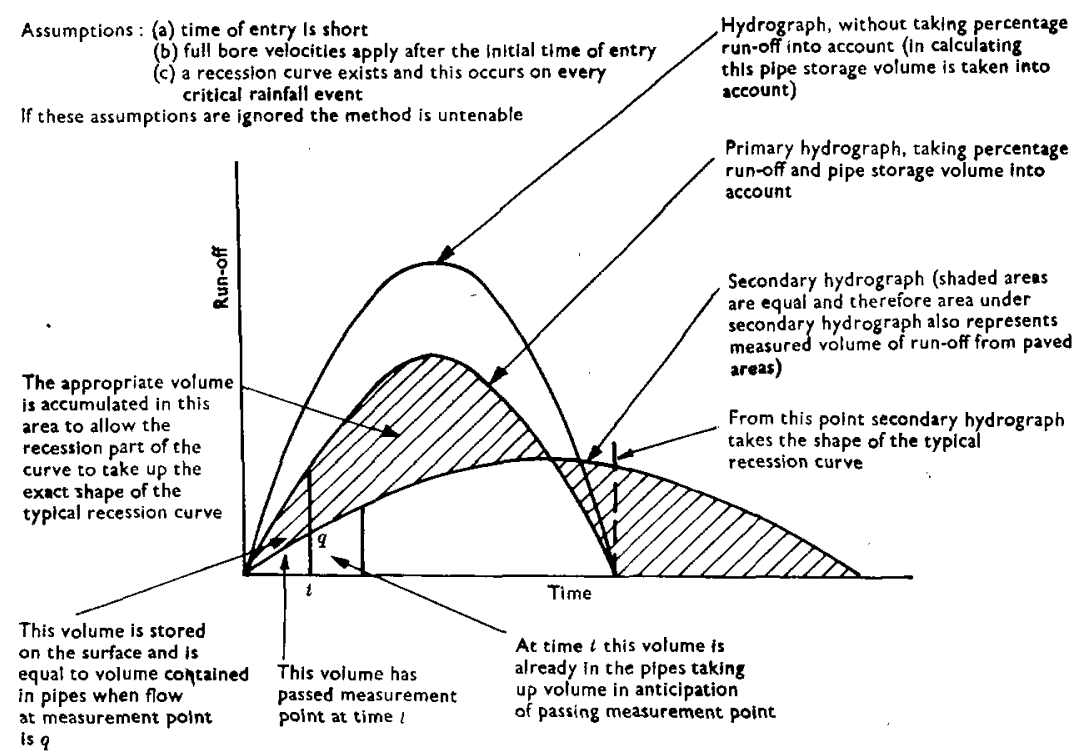

Fig. 21. Mathematical representation of TRRL method in correlation 
67. As the method is a geometrical construction, it matters not, in correlation, whether the storage occurs in the pipes, as claimed by the Author in error, or on the ground, as is definitely the case. This aspect takes on more importance in the modified method put forward by the Author.

68. If the short time of entry were correct then the time-area method of calculation would give an accurate answer for all intents and purposes as demonstrated by Newton and Painter. ${ }^{10}$ The fact is that the short time of entry is incorrect and this means that the only possible interpretation of the storage and release from storage represented by the difference between the primary and secondary hydrographs is that the storage on the ground is approximately equal to the volume of the pipes.

69. If an engineer understands the TRRL method he can show these points for himself by applying the method manually and conclude that he should not use it, as I did. If he cannot understand the method, he should not use it anyway.

70. A further interesting point which can be demonstrated by manual application is whether or not the problem of the apparent lack of constant proportional depth throughout the system is neatly overcome by maintaining the assumption over only a single pipe (see $\$ \S 16$ and 17). In fact this problem does not exist because proportional depths are reasonably constant in the recession part of the curve, where it matters, and manual application shows that the mark 2 version is just as accurate, or inaccurate, as the mark 1 version for oversize pipes.

71. It surprises me that Stall and Terstriep ${ }^{4}$ found the method inaccurate in correlation for certain areas. This suggests that when the method was applied "just as it would be in the UK' ( $\$ 22)$, percentage run-off was not taken into account, which it must be for accuracy.

72. It is difficult to know how the TRRL method could be adapted to take run-off from unpaved areas into account in correlation. However, if the intention is to determine the effect of run-off from unpaved areas on the peak flow, the Author's method is not suitable because the peak flows occur before the end of the lag times and the unpaved areas have not contributed to the peak flows ( $\$ 43$ and Figs 16-19). Thus the method does not achieve what it sets out to do.

73. In my opinion it would have been better to have introduced another variable, namely percentage run-off from paved areas, before testing for goodness of fit. More accurate correlation might well have been achieved and there would not have been need for the statement in $\$ 41$ that 'No run-off occurred from the Kira Road unpaved areas'. Surely areas were selected which were known to collect from unpaved areas and there was more than adequate time in the period of the measurements to witness events on site to confirm this or otherwise.

74. In any event, there is a basic misconception in the method. It is stated above why the original TRRL method takes surface storage into account; the proposed modified method therefore takes surface storage on unpaved areas into account twice, because a linear reservoir is introduced.

75. The geometrical construction referred to as being the basis of the TRRL method can be seen to be present in the modified version by consideration of $\S 35$; the volume of run-off from the unpaved areas is calculated by subtraction, meaning that the total volume of run-off actually experienced is again introduced into the calculation and once again the later part of the secondary hydrograph takes the shape of the assumed recession curve.

76. The Author states results of his application of the rational method but does not describe how the method was applied. I would be interested to have details of this and reasons for the selected approach.

77. With regard to the proposed modification to the TRRL method, I conclude that perhaps it is as well that its use will be restricted to East Africa for which area it was specifically developed. With regard to the original TRRL method, this is a standard design technique in UK principally because it is included in Road Note $35 .^{5}$ It is likely to give oversize pipes. Before using the method in the future engineers should 
carefully consider the implications particularly in this financial climate. Colyer and Pethick $^{11}$ concluded that the use of the TRRL and rational methods 'should certainly be reviewed in 2-3 years' time'.

\section{Mr R. B. Bulman, Consulting Engineer and Hydrologist}

In attempting to justify the adaption of the TRRL method to tropical conditions the Author has compared his results with estimates by what he calls the rational method. The term 'rational method' has been so widely and loosely used in the past few years it has become a term of abuse in hydrology and it would be better avoided for a decade or so.

79. If a critical duration method, for example that of Lloyd-Davies, ${ }^{12}$ were applied properly to the data available to the Author, much better results would be obtained than those shown in Tables 11-14.

80. In $\S 47$ the Author refers to 'the time of concentration for the catchment' as though it were fixed for all storms. It would appear that all the storms in Table 11 would produce peak discharges of less than half the capacity of the system when running full bore but without surcharge. In these circumstances the critical duration of each storm shown in Table 11 will be longer than the critical duration of the design storm which requires the sewers to run full. Could the Author indicate the discharge of each sewer system when running full bore without surcharge?

81. In Table 15 the observed peak flows are taken from Table 11. Also shown are rough estimates of the ratio of the critical duration to the critical duration of the design storm. It follows that there will be a reduction in mean intensity; the possible consequent peak discharge and percentage errors are also shown. These errors are less dependent on the size of the storm than those indicated in Tables 11-14. The average error is of the same order as that of the TRRL method in Table 11. With more information the critical duration methods properly applied could, no doubt, give even better estimates.

\section{Mr J. B. White, University of Manchester Institute of Science and Technology}

'Small showers last long, but sudden storms are short' (Shakespeare, Richard II, Act 2, Scene 1). The rational or Lloyd-Davies method ${ }^{12}$ considers hypothetically uniform storms. For such storms a time $T$ has to elapse before outflow becomes equal to the rate of rainfall input to the impermeable area. For all storms of duration $T$ or longer the peak run-off is equal to the rate of rainfall input. For shorter storms, the peak flow is less-provided the drainage area is of compact shape. It follows from the Richard II principle that the highest peak flow, from this model, is given by a storm of given frequency whose duration is equal to the time $T$. Strictly, $T$ is related to storage effects in the system but, in applying the Lloyd-Davies method, it has always been estimated from time of flow at running-full velocities.

83. Although using crude models of rainfall and of catchment response, the LloydDavies method guides the choice of design rainfall. The TRRL mark 1 method chooses design rainfall in a closely similar manner. The uncorrected hydrograph is generated from the middle part of a varying storm over a period $T$, estimated in exactly the same way as in the Lloyd-Davies method, and the varying storm is such that the mean intensity over a given time, equally distributed about the middle, is consistent with intensity versus duration relationships roughly of the form used in the earlier method. The storage correction procedure does not alter the time of concentration as such but enables the method to predict reasonably faithful hydrographs from recorded storms. The mark 1 method overcomes the most obvious defect of Lloyd-Davies as it allows varying intensity to be considered. It retains the Lloyd-Davies characteristic of choosing a design rainfall.

84. The mark 2 method does not appear to involve objective choice of rainfall. The matter becomes one for considerable thought, making one wonder whether the 
Table 15

\begin{tabular}{c|c|c|c}
\hline $\begin{array}{c}\text { Observed peak } \\
\text { flow, } \mathrm{m}^{3} / \mathrm{s}\end{array}$ & $\begin{array}{c}\text { Ratio of critical } \\
\text { duration to } \\
\text { critical duration } \\
\text { of design } \\
\text { storm }\end{array}$ & $\begin{array}{c}\text { Reduction in peak } \\
\text { discharge, } \mathrm{m}^{3} / \mathrm{s}\end{array}$ & $\begin{array}{c}\text { Error, } \\
\%\end{array}$ \\
\hline 0.81 & 4.23 & 0.48 & -41.0 \\
2.13 & $3 \cdot 13$ & 1.25 & -41.2 \\
2.06 & 3.18 & 2.06 & 0.0 \\
1.39 & 3.58 & 1.09 & -21.9 \\
1.27 & 3.70 & 1.25 & -1.3 \\
1.31 & 3.63 & 1.46 & +11.8 \\
0.86 & $4 \cdot 11$ & 1.22 & +42.3 \\
1.11 & 3.80 & 0.24 & +38.4 \\
0.37 & 5.30 & 0.66 & -35.1 \\
0.94 & 4.03 & 0.36 & -29.8 \\
0.33 & 5.60 & 1.33 & +8.6 \\
1.21 & 3.71 & +9.7 \\
\hline
\end{tabular}

Average (neglecting signs) $23 \cdot 4$

mark 2 method is safe and economical unless in the right hands. Is the mark 1 method no longer available, even for designing new, tapering systems?

85. I wish to raise a further question regarding the way in which the Author has compared rational method predictions with observed peak flows, in both his present and his earlier work. Rainfall data used to produce frequency relationships for the rational method consist of depth and duration of complete storms giving, for chosen frequency, a relationship between mean intensity and duration for complete storms. In testing the rational method against observations, rainfall data should receive the same treatment, i.e. the mean intensity for the whole storm should be used, not the mean intensity for the part of the storm which falls during the time of concentration. Using data for complete storms covers the possibility of internal compensation which may exist in the rational method when it is viewed as a whole, rather than as a mere rainfall to run-off transformation process. I suspect that the rational method is not as bad as it appears, although it is likely still to be inferior to the mark 1 method.

86. Regarding the frequency analysis aspect, the tacit assumption that the return period of the calculated run-off peak is the same as that for the rain storm used needs to be questioned. So far as the rational method is concerned, even if the method were faultless from every other point of view, this assumption would not be true. A number of storms (with duration-greater than $T$ ) which lie above the equal frequency storm curve will not give a peak flow higher than that given by the rational method. Consequently the proportion of storms giving flows equal to or greater than the calculated maximum is smaller than the proportion of storms lying above the curve. The return period of run-off is therefore longer than the return period of the rainfall relationship. The question as to how rainfall and run-off return periods relate is much more complex for the variable storms used for the TRRL methods but still merits consideration. There is no means of discovering what run-off return periods any design procedure gives without analysis of long continuous gauging of selected catchments. Does the TRRL have any such records or has gauging been discontinued? Is there any prospect of maintaining the gauges established in East Africa? 


\begin{tabular}{|c|c|c|c|}
\hline \multirow{6}{*}{ : } & \multirow{2}{*}{ 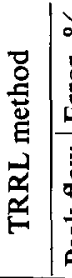 } & 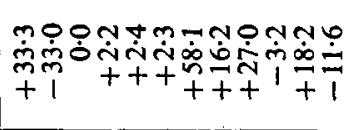 & $\stackrel{m}{\check{I}}$ \\
\hline & & \multicolumn{2}{|l|}{ 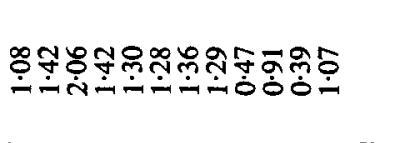 } \\
\hline & 茟 & 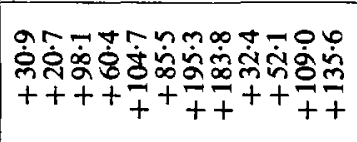 & 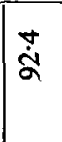 \\
\hline & 焉 & \multicolumn{2}{|l|}{ 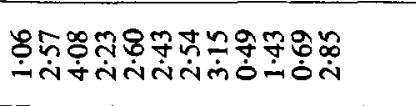 } \\
\hline & 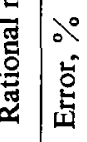 & 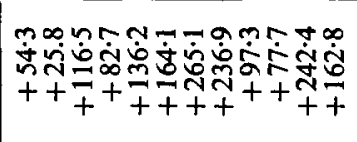 & $\begin{array}{l}n \\
\infty \\
\stackrel{n}{7} \\
+\end{array}$ \\
\hline & $\stackrel{0}{8}$ & 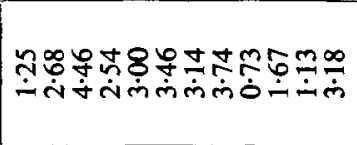 & \\
\hline \multicolumn{2}{|c|}{$\begin{array}{l}\text { Dू. } \\
\text { 总 } \\
0 \\
0\end{array}$} & 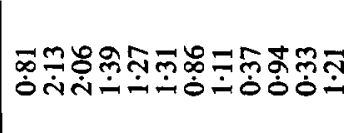 & \\
\hline \multirow{2}{*}{ 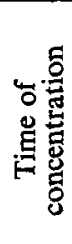 } & 苞 & 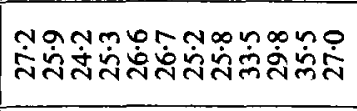 & \\
\hline & 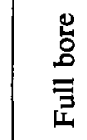 & 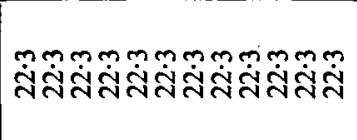 & \\
\hline \multirow{2}{*}{ 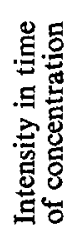 } & 胥 & 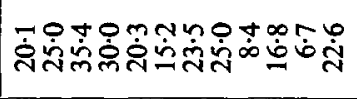 & \\
\hline & 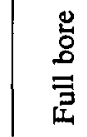 & ஸ்ં்َ & \\
\hline \multicolumn{2}{|l|}{ 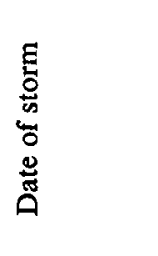 } & \multicolumn{2}{|l|}{ 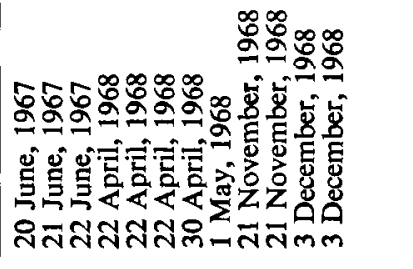 } \\
\hline
\end{tabular}




\section{Mr Wetkins}

Mr Clifton discusses the possibility of applying the concepts of the TRRL method to the design of foul sewers. This is an interesting idea, but is outside my experience. Clearly there are many differences between the characteristics of the flow of storm water and the flow of foul sewage, such as the peakiness of the former and the slow rise and fall of the latter.

88. Mr Hepworth's discussion is to a large extent relevant to reference 2. For example, the quite valid assumptions as listed in $\S 62$ apply to the UK version and to the paved area part of a tropical catchment, but not to the unpaved part. There, the paved area procedures are replaced by a linear reservoir sub-model incorporating lag times that are measured in hours. So far as his assumption $(b)$ is concerned, pipe velocities are within $\pm 20 \%$ of the full bore value for all discharges greater than $20 \%$ of the pipe capacity. ${ }^{13}$

89. In $\$ 70 \mathrm{Mr}$ Hepworth appears to have misunderstood the purpose of introducing the mark 2 version. In checking an old pipe system or designing additional branches for it the problem is that the excess capacity is unevenly distributed throughout the system and this variation from pipe to pipe needs to be taken into account.

90. In $\S 72 \mathrm{Mr}$ Hepworth suggests that the run-off from the unpaved areas cannot contribute to the peak flow because of long lag times. To reach this conclusion he has failed to understand the concept of reservoir routing through a linear reservoir. From equations (5) and (6) it will be seen that effect of the lag time on outflow from a linear reservoir following a short burst of storm rainfall is to reduce the peak flow not to delay it. The peak outflow occurs approximately at the end of the rainfall. The proportion of unpaved area run-off in the peak flow was often very large: over $80 \%$ in the case of Ofafa Jericho and approximately $30 \%$ in the case of the industrial area which had the longest lag time of any of the catchments studied.

91. The application of the modified method is not restricted to East Africa (see § 77), but is equally appropriate wherever similar topographical and climatic conditions apply. ${ }^{14}$

92. The TRRL method has become used in the UK and elsewhere not because it was incorporated in Road Note $35,{ }^{5}$ which is not mandatory but informative, but rather because it is a practical and useful design tool that has now stood the test of time over 13 years since its first publication.

93. Both Mr Hepworth and Mr Bulman question the use of the term 'rational method' to describe the alternative to the TRRL method examined in the Paper. As East African catchments were being examined, the technique with which the TRRL method was compared was the current standard method in East Africa. Advice was taken from engineers in East Africa and the method was applied accordingly to their current practice. This seemed to be the only way to determine the likely effect of the introduction of the new method.

94. The time of concentration of each catchment was calculated by adding the time of entry to the flow time determined by the full bore velocity down the longest branch of the system. Mr Bulman's observations ( $\$ \$ 80$ and 81 ) are quite correct that for the recorded storms the flows were well below capacity in most cases, and that therefore the rational method results would have appeared in a more favourable light had part full rather than full bore velocities been used. However, the reduction in the peak flow estimate would have been much smaller than that suggested by Mr Bulman. All the storms for the Nairobi area have been recalculated from the original data in this way (Table 16). The average error for the rational method has been reduced from $138.5 \%$ to $92.4 \%$, as compared with the error of $17.3 \%$ for the TRRL method. However, far from regarding 'rational method' as a term of abuse ( $\$ 78)$, Road Note 35 has been re-issued and reiterates the firm belief that the method is perfectly acceptable under certain circumstances and states what those circumstances are.

95. I can assure Mr White that the mark 2 TRRL method is not less objective in its 


\section{DISCUSSION}

rainfall input than the mark 1 version, but more so. The central part of the storm profile was isolated in the mark 1 version not because of any desire for objectivity but merely to save computer time with the relatively primitive machines available at the time. These days this economy is not necessary and the mark 1 version is no longer available-it does in any case give exactly the same design as the mark 2 version provided that the system is new and tapering as specified by $\mathrm{Mr}$ White ( $\$ 84$ ).

96. I am grateful to $\mathrm{Mr}$ White for drawing attention to the problem of relating occurrence intervals of floods to those of the storms that generate them. To my mind this is the aspect of flood hydrology least well investigated. It is undoubtedly one, and possibly the main, contributing cause of sewer systems being surcharged less frequently than the design storm occurrence interval would suggest. The TRRL is no longer active in this field but the Institute of Hydrology and the Hydraulics Research Station have studies under way. I hope that any solution will build on the knowledge acquired during research in the UK and in East Africa, and on the experience gained with the considerable use that the TRRL method has had.

\section{References}

9. British Standards Insitutution. Sewerage, CP 2005. British Standards Institution, London, 1968.

10. Newton S. G. and Painter R. B. A mathematical examination of urban run-off prediction. Proc. Instn Civ. Engrs, Part 2, 1974, 57, Mar., 143-157.

11. Colyer P. J. and Pethick R. W. Storm drainage design methods-a literature review. Hydraulics Research Station, Wallingford, 1976, Internal report 154.

12. Lloyd-Davies D. E. The elimination of storm-water from sewerage systems. Proc. Instn Civ. Engrs, 1905, Part II, 164, 41-67.

13. Hydraulics Research Station. Tables for the hydraulic design of storm-drains, sewers and pipe lines. HMSO, London, 1963, Hydraulics Research Paper 4. 